\title{
ОСОБЕННОСТИ ВЛИЯНИЯ ЭКОЛОГИЧЕСКИХ ФАКТОРОВ НА ПОКАЗАТЕЛИ ГУМОРАЛЬНОГО ИММУНИТЕТА ОРГАНИЗМА ЧЕЛОВЕКА
}

\section{PECULIARITIES OF THE INFLUENCE OF ENVIRONMENTAL FACTORS ON THE HUMORAL IMMUNITY INDICATORS OF HUMAN BODY}

\section{N. Zakharov \\ I. Kondrashova N. Kondykova}

Summary. The paper presents the results of studies of the content of immunoglobulins of different classes in the saliva of qualified athletes aged 19-22 living in ecologically different areas. The concentration of immunoglobulins is one of the most important characteristics of the state of humoral immunity. The impact of environmental factors on the state of humoral immunity and the immunological status of the organism has been assessed. Immunoglobulin concentrations were determined by one-dimensional radial immunodiffusion. A decrease in the concentration of immunoglobulins in the saliva of athletes under the influence of intensive physical activity against the background of adverse environmental factors of radiation and chemical nature was revealed. There is a significantly lower concentration of immunoglobulin $A$ in the saliva of athletes from adverse environmental areas compared to clean areas. Changes in immunity corresponding to the first stage of changes in the immunological parameters, when immunodeficiency states do not arise yet, but the risk of developing immunodeficiency is quite high are noted against the background of the combined effect of the adverse environmental factors and high athletes' physical activity.

Keywords: environmental factors, immune status, immunoglobulins, humoral immunity, athletes.
Захаров Никита Евгеньевич

К.б.н., дочент, ФГБОУ ВО «Брянский государственный инженерно-технологический университет» zaxarov1602@yandex.ru

Кондрашова Ирина Николаевна

К.п.н., дочент, ФГБОУ ВО «Орловский государственный университет имени И.С. Тургенева» eco-kondrashova@yandex.ru

Кондыкова Наталия Николаевна К.с.-Х.н., дочент, ФГБОУ ВО «Орловский государственный университет имени И.С. Тургенева» nkondykova@yandex.ru

Аннотация. Представлены результаты исследований содержания иммуноглобулинов различных классов в слюне квалифицированных спортсменов 19-22 лет, проживающих в экологически различных районах. Концентрация иммуноглобулинов является одной из важнейших характеристик состояния гуморального иммунитета. Проведена оценка влияния экологических факторов на состояние гуморального иммунитета и иммунологического статуса организма. Определение концентрации иммуноглобулинов проводилось методом одномерной радиальной иммунодиффузии. Выявлено снижение концентрации иммуноглобулинов в слюне спортсменов под влиянием интенсивных физических нагрузок на фоне воздействия неблагоприятных экологических факторов радиационно-химической природы. Отмечена достоверно более низкая концентрация иммуноглобулина А в слюне спортсменов из экологически неблагополучных районов по сравнению с чистыми территориями. На фоне сочетанного воздействия неблагоприятных экологических факторов и высоких физических нагрузок у спортсменов отмечены изменения иммунитета, соответствующие первой стадии изменений иммунологических показателей, когда иммунодефицитные состояния еще не возникают, однако риск развития иммунной недостаточности достаточно велик.

Ключевые слова: экологические факторы, иммунный статус, иммуноглобулины, гуморальный иммунитет, спортсмены.

нопатологические состояния, приводящие к различным заболеваниям: респираторным и аденовирусным инфекциям, аллергическим и аутоиммунным состояниям $[1,5]$. Иммунная система, как одна из ключевых интегральных и регуляторных систем человеческого организма, является индикаторной системой экологического неблагополучия, чутко реагирующей на изменение условий окружающей среды. Критерии факторов неспецифического иммунитета отражают физиологическое состояние организма, его потенциальную возможность адаптироваться 
к различным воздействиям внешней и внутренней среды [8]

В то же время, учитывая важную роль иммунной системы в поддержании механизмов гомеостаза, актуальным является изучение иммунного статуса спортсменов. Контроль за состоянием иммунной системы у спортсменов в процессе тренировок и соревнований - объективный и чувствительный метод оценки состояния резистентности организма и степени адаптации его к спортивным нагрузкам $[9,10]$. Повышенная напряженность тренировочно-соревновательного процесса в спорте оказывает на организм спортсмена экстремальное психофизическое воздействие, которое может быть причиной возникновения серьезных нарушений деятельности ряда органов и систем. При длительных и интенсивных физических нагрузках у лиц, занимающихся спортом, могут наблюдаться серьезные колебания показателей системы иммунитета со стороны фагоцитарного, Т- и В-клеточного звеньев, что в определенных случаях ведет к развитию вторичных иммунодефицитных состояний, лимитирующих физическую работоспособность. В практике спорта сегодня также остро стоит проблема повышенной заболеваемости спортсменов вследствие чрезмерных физических и психоэмоциональных нагрузок $[3,4,6]$.

Одной из важнейших характеристик состояния гуморального иммунитета и функциональной активности В-лимфоцитов является количественное определение неспецифических иммуноглобулинов в сыворотке крови и биологических жидкостях. Содержание иммуноглобулинов в крови как один из факторов, обеспечивающих гомеостаз и резистентность, отражает процесс напряжения физиологических систем организма под влиянием физических нагрузок. Современные данные указывают на активное участие иммунной системы в развертывании адаптационного процесса [11]. Результаты многочисленных исследований свидетельствуют, что занятия физкультурой и спортом оказывают благоприятное воздействие на показатели естественного иммунитета. Однако в ряде работ показано, что современный спорт может оказывать угнетающее действие на систему иммунитета $[6,7,11]$.

Таким образом, изучение содержания иммуноглобулинов различных классов в слюне спортсменов из экологически различных районов представляется нам актуальной проблемой и имеет прикладное значение для медицины и соревновательной деятельности как критерий адаптационных возможностей человека при интенсивных физических нагрузках на фоне воздействия неблагоприятных факторов окружающей среды.

Целью исследования являлось изучение состояния гуморального иммунитета спортсменов из экологически различных районов на основании анализа содержания иммуноглобулинов в слюне.

Методы и организация исследований. В соответствии с целями и задачами настоящей работы была проведена количественная оценка содержания иммуноглобулинов как важнейшего показателя состояния гуморального иммунитета в слюне лиц, являющихся квалифицированными спортсменами, из экологически различных районов. Проведены исследования по оценке влияния экологических факторов на состояние гуморального иммунитета и иммунологического статуса организма в условиях экологического неблагополучия.

Были обследованы лица в возрасте 19-22 лет, являющиеся квалифицированными спортсменами, и проживающие в районах с разным уровнем территориальных техногенных нагрузок. Все обследованные имели спортивные звания мастеров спорта и являлись представителями спортивных единоборств (вольная борьба, самбо, дзюдо), тяжелой атлетики, пауэрлифтинга. Было обследовано 28 человек, обследованные были разделены на две группы согласно экологическим условиям районов проживания. В первую группу вошли 13 спортсменов, проживающих в экологически условно чистом районе (город Брянск). Вторую группу составили 15 спортсменов, проживающих и тренирующихся в районах, где отмечается повышенный радиационный фон и территориальные пестицидные нагрузки (г. Клинцы и г. Новозыбков). Экологическая оценка районов проживания обследованных спортсменов проведена на основе официальных статистических данных по Брянской области.

С целью изучения показателей неспецифического гуморального иммунитета проводилось определение концентрации иммуноглобулинов различных классов $(\lg A$, $\operatorname{lgM}, \operatorname{lgG}$ в в биологической жидкости (слюне) методом одномерной радиальной иммунодиффузии в агаровом геле по Манчини при помощи стандартного диагностикума. Результаты исследования обработаны статистически.

\section{Результаты исслеАований и их обсужАение}

Анализ статистических материалов по техногенному загрязнению районов Брянской области [2] позволил выделить две экологические группы районов проживания обследованных спортсменов - экологически благополучный (контроль) (I ЭГ), и районы, испытывающие высокий уровень радиационно-химического загрязнения территорий (II ЭГ).

Анализ содержания иммуноглобулинов различных классов в слюне квалифицированных спортсменов, про- 
живающих в экологически различных районах, позволил установить, что у спортсменов из экологически условно чистых районов содержание в слюне иммуноглобулина $G$, активного против грамотрицательных бактерий, токсинов, вирусов, агглютинирующего и лизирующего чужеродные клетки, составляет 814,8 $\pm 25,36$ мг/100

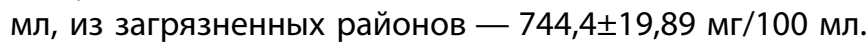
По данным литературных источников [7, 9], средним значением содержания иммуноглобулина $\mathrm{G}$ в слюне здоровых людей 19-22 лет является 1086 мг/100 мл. В обеих группах обследованных спортсменов наблюдается снижение исследуемого показателя относительно средних значений, не выходящее, однако, за пределы физиологической нормы. При этом, однако, содержание иммуноглобулина G в слюне спортсменов из экологически неблагополучных районов превышает нижние значения возрастной нормы на лишь на 3,3\%. При анализе индивидуальных показателей содержания иммуноглобулина G в группе спортсменов из экологически чистого района отклонений от возрастной нормы по данному классу иммуноглобулинов выявлено не было. Среди лиц из загрязненных районов отмечено снижение концентрации иммуноглобулина G ниже нормативных значений у $13 \%$ обследованных.

Концентрация иммуноглобулина M, образующегося на ранних этапах иммунного ответа и запускающего биосинтез lgG, в слюне спортсменов из I ЭГ составляет

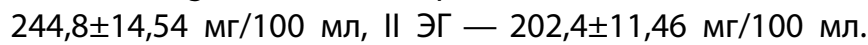
По данному классу иммуноглобулинов не выявлено случаев выхода исследуемых показателей за пределы возрастной нормы. При этом, однако, наблюдается снижение концентрации иммуноглобулина М относительно средних возрастных нормативных показателей (321 мг/100 мл) в обеих группах обследованных спортсменов, несколько более выраженное у лиц из загрязненных районов.

Концентрация иммуноглобулина А, способного распознавать вирусы и бактериальные токсины, в слюне спортсменов из экологически чистого района $(112,3 \pm 7,28$ мг/100 мл) соответствует средним нормативным значениям исследуемого показателя здоровых людей (106 мг/100 мл). При этом выявлено значительное снижение концентрации иммуноглобулина А в слюне спортсменов из загрязненных районов $(63,2 \pm 3,37$ г/100 мл) как по сравнению с показателями представителей І ЭГ, так и по сравнению с нормативными значениями. Содержание иммуноглобулина А у представителей II ЭГ находится на нижней границе возрастной нормы (61 мг/100 мл). При анализе индивидуальных показателей содержания иммуноглобулина А в I ЭГ выходов за пределы физиологической нормы выявлено не было, в то время как у $60 \%$ представителей II ЭГ отмечено снижение концентрации иммуноглобулина А ниже нормативных значений.
Нами отмечена более низкая концентрация иммуноглобулинов всех классов в слюне спортсменов из загрязненных районов по сравнению со сверстниками, проживающими на условно чистых территориях. Для концентрации иммуноглобулина $G$ различия составляют 9,4\%, иммуноглобулина М - 20,8\%, иммуноглобулина $A-77,7 \%$. При этом содержание иммуноглобулина А в слюне представителей условно чистого района оказывается достоверно выше $(p \leq 0,01)$ аналогичного показателя спортсменов из загрязненных районов.

В ходе наших исследований была предпринята попытка выявить особенности показателей гуморального звена системы иммунитета спортсменов из экологически различных районов в период высоких спортивных нагрузок. В ряде источников приводятся данные о значительных колебаниях концентрации иммуноглобулинов в биологических жидкостях спортсменов под воздействием интенсивных тренировочных воздействий $[10,11]$. Показана зависимость показателей иммунологической реактивности организма от объема и интенсивности нагрузок. Вместе с тем имеются данные о наличии изменений в иммунном статусе лиц, проживающих в экологически неблагополучных районах, возрастании уровня хронических заболеваний, функциональном снижении активности системы иммунитета под воздействием неблагоприятных экологических факторов $[4,5,8]$.

Анализ содержания иммуноглобулинов различных классов в слюне спортсменов позволил нам выявить тенденцию к снижению концентрации иммуноглобулинов классов A, G, М у лиц, проживающих в районах экологического неблагополучия. Выявлена достоверно более низкая $(p<0,01)$ концентрация иммуноглобулина А в слюне спортсменов из экологически неблагополучных районов по сравнению с чистыми территориями. Нарушения иммунного статуса при больших тренировочных нагрузках могут привести к перенапряжению организма, что повлечет за собой снижение его резистентности к действию факторов внешней и внутренней среды. При больших нагрузках в фазе недовосстановления или кумуляции утомления в организме спортсменов возникает конкурентная борьба за эндогенный и экзогенный белок, который идет главным образом на восстановление нервно-мышечного аппарата. В фазе декомпенсации реакции иммунной системы, возникающей в результате сочетанного стрессового воздействия неблагоприятных экологических факторов и физических нагрузок высокой интенсивности, регистрируется значительное угнетение большинства гуморальных, секреторных и клеточных показателей иммунитета, что свидетельствует о срыве адаптации, истощении резервов иммунитета. Титры иммуноглобулинов могут значительно снижаться, приводя к функциональным сбоям в работе иммунной системы. 


\section{Зак^ючение}

Таким образом, в результате наших исследований выявлено снижение концентрации иммуноглобулинов классов A, G, М в слюне квалифицированных спортсменов 19-22 лет под влиянием интенсивных физических нагрузок на фоне воздействия неблагоприятных экологических факторов радиационно-химической природы. Аналогичные показатели спортсменов, проживающих в экологически условно чистом районе, характеризуются соответствием нормативным значениям с незначительной тенденцией к снижению содержания иммуноглобулинов классов G и М относительно средненормативных значений. Выявлены достоверно более высокие $(p \leq 0,01)$ показатели содержания иммуноглобулина А в слюне представителей условно чистого района по сравнению со спортсменами из загрязненных районов. Для лиц, длительное время испытывающих воздействие неблагоприятных физических, химических, био- логических факторов, характерен стадийный характер изменения ряда показателей иммунитета. Первая стадия характеризуется снижением уровня иммуноглобулина А, вторая - снижение уровней иммуноглобулинов всех классов. Для этих стадий часто характерно отсутствие клинических проявлений.

На основании проведенных исследований можно предположить, что изменения иммунитета, соответствующие первой стадии изменений иммунологических показателей, у спортсменов из обследованных нами загрязненных районов возникают на фоне сочетанного воздействия неблагоприятных экологических факторов и физических нагрузок высокой интенсивности. На данной стадии иммунодефицитные состояния еще не возникают, однако риск возникновения третьей и четвертой стадий, когда происходит развитие иммунной недостаточности, проявляющееся, прежде всего, наличием инфекционного синдрома, достаточно велик.

\section{ЛИТЕРАТУРА}

1. Гегерь Э.В. Методы оценки эколого-гигиенического состояния территорий / Э.В. Гегерь, Г.П. Золотникова, В.А. Капцов // Гигиена и санитария.— 2019.— Т. 98. — № 12.— С. 1338-1341.

2. Годовой доклад 06 экологической ситуации в Брянской области в 2019 г. Природные ресурсы и окружающая среда Брянской области. / Составители: Г.В. Левкина, О.А. Иванченкова, А.А. Луцевич. // Департамент природных ресурсов и экологии Брянской области.- Брянск: 000 «Издательство «читай-город, 2020.- 276 с.

3. Золотникова Г.П. Адаптационный потенциал организма лиц подросткового и юношеского возраста при спортивных нагрузках в современных экологических условиях. Монография / Г.П. Золотникова, Н.Е. Захаров. - Брянск: Изд-во «Белобережье», 2018 г. — 156 с.

4. Золотникова Г.П. Состояние иммунологической резистентности организма учащихся при спортивных нагрузках в современных условиях / Г.П. 30лотникова, Н.Е. Захаров // Ежегодник НИИ фундаментальных и прикладных исследований. — 2019. — № 1 (11). — C. 50-52.

5. Золотникова, Г.П. Выявление рисков развития экозависимой патологии у населения в районах, ранжированных по степени техногенного загрязнения / Г.П. Золотникова, Э.В. Гегерь // Экология человека.— 2018.— № 4. — С. 10-17.

6. Кудряшов В.С. Заболеваемость и иммунологическая реактивность профессиональных спортсменов / В.С. Кудряшов, О.А. Толстой, В.Н. Цыган, Е.Г. Мокеева // Актуальные проблемы физической культуры, спорта и туризма. Материалы ХІІІ Международной научно-практической конференции, посвященной 70-летию кафедры физического воспитания УГАТУ.— 2019._- С. 447-448.

7. Мокеева, Е.Г. Механизмы формирования иммунных дисфункций у высококвалифицированных спортсменов / Е.Г. Мокеева, Ю.В.Яковлев // Теория и практика физической культуры. - 2014. — № 6. - С. 43-45.

8. Парахонский А.П. Нарушения иммунной системы при действии экологических факторов / А.П. Парахонский // Стратегии развития современной науки. Сборник научных статей. - Москва, 2019. - С. 26-29.

9. Рахманов Р.С. Оценка влияния физических нагрузок на гуморальный иммунитет спортсменов / Р.С. Рахманов, Е.С. Богомолова // Медицина экстремальных ситуаций. - 2020.- № 2.- С. 231-236.

10. Суздальницкий Р.С. Новые подходы к пониманию спортивных стрессорных иммунодефицитов / Р.С. Суздальницкий, В.А. Левандо // Теория и практика физической культуры.-2003.— № 1.- С. 18-22.

11. Толстой 0.А. Синдром иммунной дисфункции у высококвалифицированных спортсменов и его коррекция цитаминами / 0.А. Толстой, В.Н. Цыган // Известия Российской Военно-медицинской академии. — 2019.— - Т. 38. — № S3.— С. 249-255. 